\title{
Effect of Female Chronic Hepatitis C Virus on Her Male Partner Sexual Function
}

\author{
A.A.Saleh, A.M.Hamed, and N.A.Omer
}

Dermatology, Venereoloy and Andrology Dept, Faculty of Medicine, Banha Univ., Egypt

E-mail: yasenelghazoly@gmail.com

\begin{abstract}
Human sexuality is the way people express themselves as sexual beings. This involves biological, erotic, physical, emotional, social or spiritual feeling and behaviors. Sexual dysfunction refers to a problem occurring during any phase of the sexual response cycle that prevents the individual or couple from experiencing satisfaction during the sexual activity. The aim of this work is to assess the sexual function of the male partners of females with chronic hepatitis $\mathrm{c}$ virus. This was a cross sectional study that was conducted on 100 males $(<45$ years old) married to sexually active female partners having chronic hepatitis C (group A) and 100 age matched males married to healthy individuals as control (group B) all subjects were recruited from Banha University Hospital (hepatology unit) and National Liver Institute at EL-Menofia during the period from January 2017 to December 2018. Data was collected using the International Index of Erectile Function (IIEF) questionnaire. we noticed that males married to female partners who receive treatment of HCV had high scores of sexual functions than males married to untreated female partners regarding to all items of sexual domains of IIEF ( $p<0,001)$. The results of this study provide quantifiable risk information for counseling long-term monogamous heterosexual couples in which one partner has chronic HCV infection. In addition to the extremely low estimated risk for $\mathrm{HCV}$ infection in sexual partners, the lack of association with specific sexual practices provides unambiguous and reassuring counseling messages.
\end{abstract}

Keywords: Sexuality, Hepatitis C Virus,Cross Sectional.

\section{Introduction}

Human sexuality is the way people express themselves as sexual beings. This involves biological, erotic, physical, emotional, social or spiritual feeling and behaviors.

Sexual dysfunction refers to a problem occurring during any phase of the sexual response cycle that prevents the individual or couple from experiencing satisfaction during the sexual activity [1].

Sexual Disorders are categorized into four main sections: Firstly, sexual desire disorders are defined as general persistent or recurrent deficiency of sexual fantasies or sexual activity leading to disturbance with causing marked distress. Secondly, sexual arousal disorders explained as persistent or recurrent inability to attain or to maintain sexual response until the end of intercourse. This leads to marked distress. Thirdly, orgasmic disorder defined as persistent or recurrent delay or absence of orgasm following a normal sexual excitement phase. Lastly, sexual pain disorders characterized as recurrent or persistent pain associated with sexual intercourse [2].

Sexual dysfunction may be due to physical or psychological causes: Many physical and/or medical conditions can cause problems with sexual function. These conditions include diabetes, heart and vascular (blood vessel) disease, neurological disorders, hormonal imbalances, chronic diseases such as kidney or liver failure, alcoholism and drug abuse. In addition, the side effects of some medications, including some antidepressant drugs, can affect sexual function. Psychological causes include work-related stress and anxiety, concern about sexual performance, marital or relationship problems, depression, feelings of guilt,

concerns about body image, and the effects of a past sexual trauma [3].

Hepatitis C Virus (HCV) infection is a major global health problem because of the progression to cirrhosis and hepatocellular cancer, Egypt is the country with the highest HCV prevalence in the world; in 2008, the Egyptian Demographic Health Survey (EDHS), which was conducted on a large nationally representative sample, estimated the prevalence of $\mathrm{HCV}$ antibodies and HCV RNA, among the 15-59 years [4].

Sexual transmission of hepatitis $\mathrm{C}$ is uncommon. Studies examining the risk of $\mathrm{HCV}$ transmission between heterosexual partners, when one is infected and the other is not, have found very low risks. Sexual practices that involve higher levels of trauma to the anogenital mucosa, such as anal penetrative sex, or that occur when there is a concurrent sexually transmitted infection, including HIV or genital ulceration, present greater risks [5].

Hepatitis $\mathrm{C}$ is commonly accompanied by fatigue and depression, followed by a decreased interest in sex. Additionally, antiviral medications typically used to battle Hepatitis $\mathrm{C}$ may cause sexual dysfunction and decreased libido. Sexual dysfunction is the most frequently encountered side effect of many antidepressant medications used to treat the depression and anxiety associated with Hepatitis C combination treatment. When discontinued, the medication-induced sexual dysfunction typically vanishes. Due to its prevalence in chronic Hepatitis $\mathrm{C}$ patients, openly discussing sexual problems with a physician can help to identify if the source is the disease, prescribed medications or some other condition [6].

Regardless of gender or whether or not undergoing combination therapy, living with 
Hepatitis C can spawn sexual dysfunction. Even though it is a subject that most of people prefer to avoid, speaking up on impaired sexual function or interest can prompt your physician to re-evaluate their liver management plan. Since a healthy sex life is one expression of physical, spiritual and emotional health, supporting this component can dramatically increase someone's quality of life. By discussing this sensitive topic, people with Hepatitis $\mathrm{C}$ can get the help needed to reclaim this most basic part of being human [7].

\section{Patients and methods}

\subsection{Participants}

This was a cross sectional study that was conducted on 100 males ( $<45$ years old) married to sexually active female partners having chronic hepatitis C (group A) and 100 age matched males married to healthy individuals as control (group B) all subjects were recruited from Banha University Hospital (hepatology unit) and National Liver Institute at EL-Menofia during the period from January 2017 to December 2018. Data was collected using the International Index of Erectile Function (IIEF) questionnaire.

\subsection{Ethical consideration}

The study was approved by the ethical committee of the Faculty of Medicine, Banha University. Written informed consent was taken from each participant after explaining the purpose of the study and ensuring that there was no obligation to participate. The consent form was developed according to the international ethical guidelines for medical research involving human and quality improvement of the Egyptian Ministry of Health.

\subsection{Inclusion criteria}

- Males (<45 years old) married to sexually active female's partners having chronic hepatitis C.

- Age matched males married to healthy individual as control.

- Ability to read and write so that men can fill the questionnaire anonymously.

\subsection{Exclusion criteria}

- Participants who refuse to provide study consent.

- Patients treated with medications which may affect the sexual life e.g.: chemotherapy.

- Participants with psychiatric problems as they may affect their sexual function.

- Males with sexually transmitted diseases

- Males with concomitant Hepatitis B (HBV) or Human immunodeficiency virus(HIV).

- Drug abuse.

\subsection{Methods}

The methodology of this study will be described according to:

I-Administrative Design

II-Technical Design

III- Statistical Design

\section{I-Administrative Design}

The work will start after obtaining an approval from Department of Dermatology and Andrology and Research Ethics Committed in Banha faculty of Medicine.

\section{II-Technical Design}

A-Place of study: The participants will be questioned in Banha University Hospital and National Liver Institute at El Menofyia.

B- Study sample: The study will be including the male partners of females with chronic hepatitis $\mathrm{C}$ virus who were recruited from Banha University Hospital (hepatology unit)) \& National Liver Institute at EL-Menoufia.

\section{The participants were subjected to}

1- History: History was taken from all patients with special emphasis:

Personal history: Name, age, resident, occupation, marital status, level of education and special habits of medical importance particularly smoking and alcohol intake and history of female partner (name, age, occupation, level of education, compensation to disease, treatment, duration of treatment...).

2-Questionnaire: The questionnaire will be explained to the men before taking their informed consent. The tool used in the study will be the International Index of Erectile Function (IIEF) which is validated, multidimensional, selfadministrated investigation that has been found useful in the clinical assessment of erectile dysfunction and treatment outcomes in clinical trials. There are 15 questions that examine the four main domain of male sexual function: erectile dysfunction, orgasmic dysfunction, sexual desire and intercourse satisfaction [8].

\subsection{Statistical Analysis}

Data were fed to the computer and analyzed using IBM SPSS software package version 20.0. (Armonk, NY: IBM Corp) Qualitative data were described using number and percent. The Kolmogorov-Smirnov test was used to verify the normality of distribution Quantitative data were described using mean, standard deviation Significance of the obtained results was judged at the $5 \%$ level. 


\section{3-Results}

Table (1) Comparison between two groups regarding demographic data $(n=200)$.

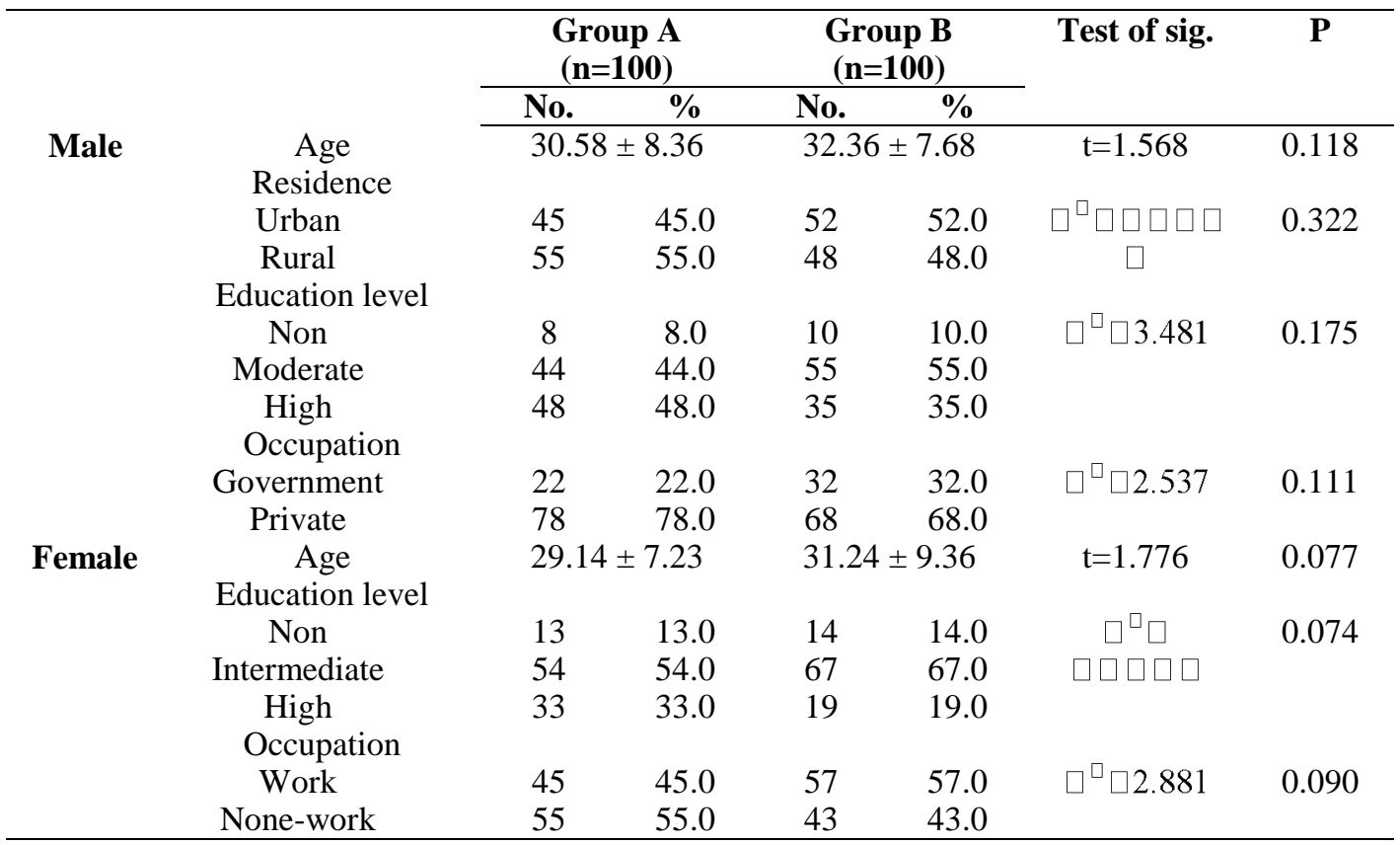

No statistically significance difference in sexual functions in males married to females with CHC (Group A) compared with males married to healthy individuals as control (Group B).

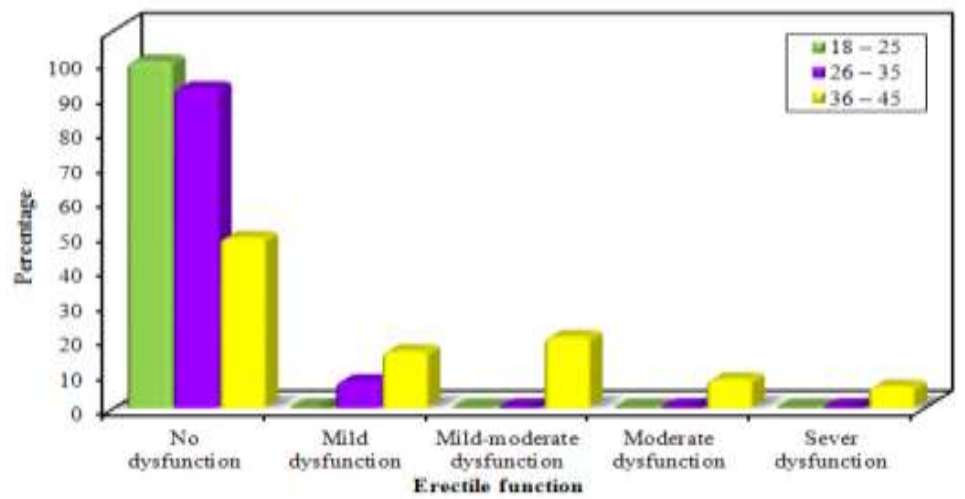

Fig (1) Relation between age of male and erectile function in group A $(n=100)$.

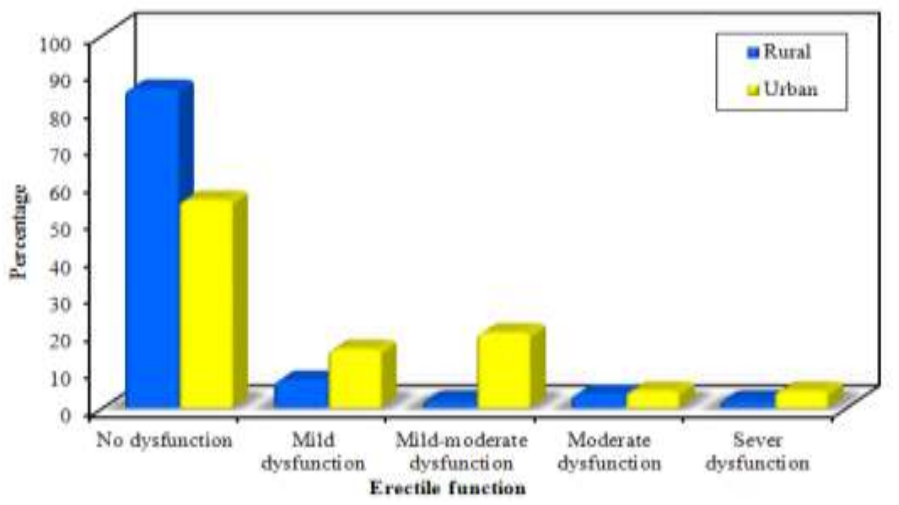

Fig (2) Relation between residence of male and erectile function in group A $(n=100)$ 


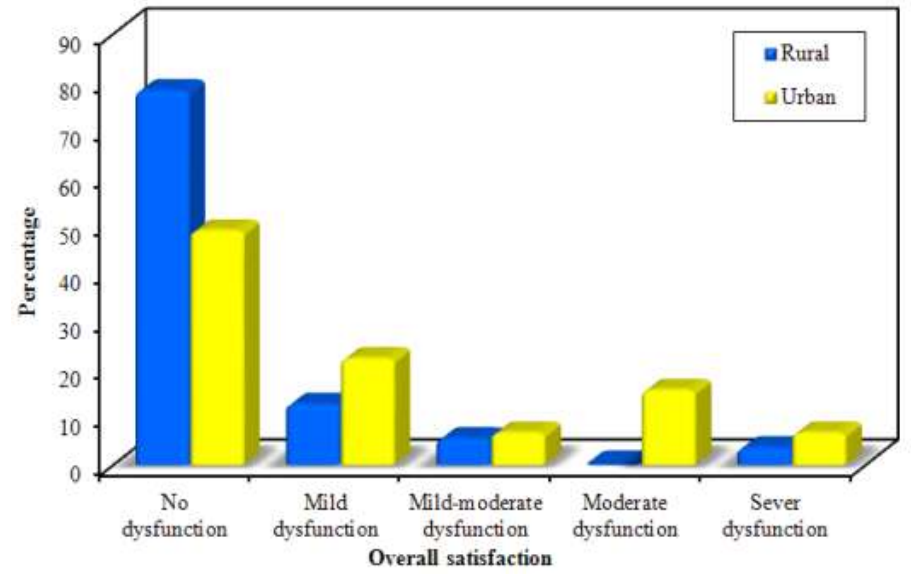

Fig (3) Relation between residence of male and overall satisfaction in group A $(\mathrm{n}=100)$.

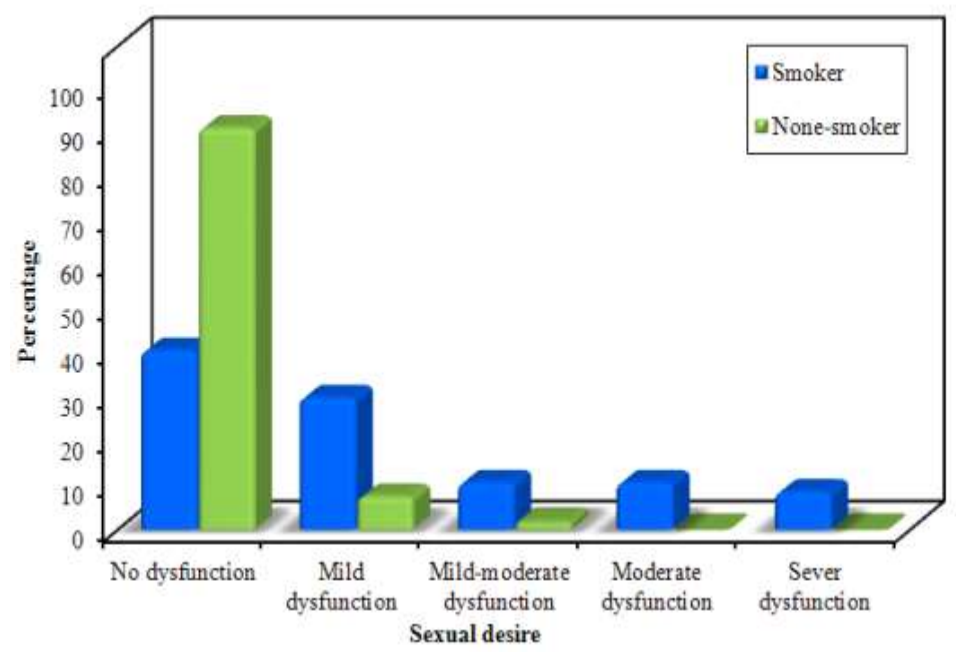

Fig (4) Relation between Special habits and sexual desire in group $A(n=100)$.

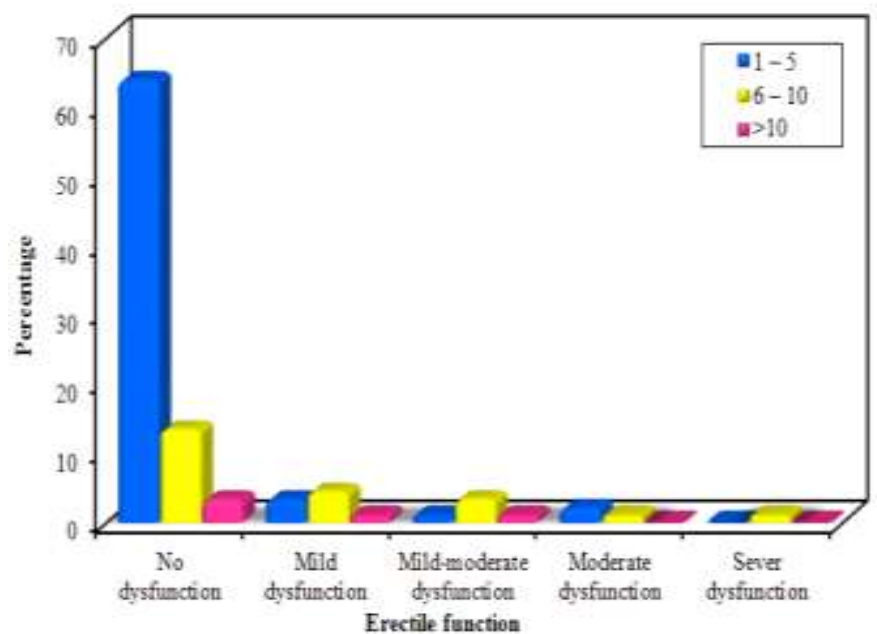

Fig (5) Relation between duration of HCV infection of female partners and erectile function of males in group $A(n=100)$. 
Table (2) Relation between liver status of female partners and all types of sexual domains of IIEF in group A $(n=100)$.

\begin{tabular}{|c|c|c|c|c|c|c|}
\hline \multirow{3}{*}{ Types of sexual domains } & \multicolumn{4}{|c|}{ Compensation of female patients } & \multirow{3}{*}{$\mathbf{X}^{2}$} & \multirow{3}{*}{${ }^{M C} \mathbf{p}$} \\
\hline & \multicolumn{2}{|c|}{$\begin{array}{c}\text { Compensated } \\
(\mathrm{n}=86)\end{array}$} & \multicolumn{2}{|c|}{$\begin{array}{c}\text { None-compensated } \\
(n=14)\end{array}$} & & \\
\hline & No. & $\%$ & No. & $\%$ & & \\
\hline \multicolumn{7}{|l|}{ Erectile function } \\
\hline No dysfunction & 72 & 83.7 & 0 & 0.0 & \multirow{5}{*}{$46.424^{*}$} & \multirow{5}{*}{$<0.001^{*}$} \\
\hline Mild dysfunction & 8 & 9.3 & 3 & 21.4 & & \\
\hline Mild-moderate dysfunction & 4 & 4.7 & 6 & 42.9 & & \\
\hline Moderate dysfunction & 2 & 2.3 & 2 & 14.3 & & \\
\hline Sever dysfunction & 0 & 0.0 & 3 & 21.4 & & \\
\hline \multicolumn{7}{|l|}{ Orgasmic function } \\
\hline No dysfunction & 66 & 76.7 & 0 & 0.0 & \multirow{5}{*}{$42.518^{*}$} & \multirow{5}{*}{$<0.001^{*}$} \\
\hline Mild dysfunction & 15 & 17.4 & 4 & 28.6 & & \\
\hline Mild-moderate dysfunction & 3 & 3.5 & 5 & 35.7 & & \\
\hline Moderate dysfunction & 2 & 2.3 & 2 & 14.3 & & \\
\hline Sever dysfunction & 0 & 0.0 & 3 & 21.4 & & \\
\hline \multicolumn{7}{|l|}{ Sexual desire } \\
\hline No dysfunction & 67 & 77.9 & 0 & 0.0 & \multirow{5}{*}{$39.736^{*}$} & \multirow{5}{*}{$<0.001^{*}$} \\
\hline Mild dysfunction & 11 & 12.8 & 7 & 50.0 & & \\
\hline Mild-moderate dysfunction & 2 & 2.3 & 4 & 28.6 & & \\
\hline Moderate dysfunction & 2 & 2.3 & 3 & 21.4 & & \\
\hline Sever dysfunction & 4 & 4.7 & 0 & 0.0 & & \\
\hline \multicolumn{7}{|l|}{ Intercourse satisfaction } \\
\hline No dysfunction & 65 & 75.6 & 0 & 0.0 & \multirow{5}{*}{$36.450^{*}$} & \multirow{5}{*}{$<0.001^{*}$} \\
\hline Mild dysfunction & 11 & 12.8 & 6 & 42.9 & & \\
\hline Mild-moderate dysfunction & 4 & 4.7 & 2 & 14.3 & & \\
\hline Moderate dysfunction & 2 & 2.3 & 5 & 35.7 & & \\
\hline Sever dysfunction & 4 & 4.7 & 1 & 7.1 & & \\
\hline \multicolumn{7}{|l|}{ Overall satisfaction } \\
\hline No dysfunction & 65 & 75.6 & 0 & 0.0 & \multirow{5}{*}{$36.450^{*}$} & \multirow{5}{*}{$<0.001^{*}$} \\
\hline Mild dysfunction & 11 & 12.8 & 6 & 42.9 & & \\
\hline Mild-moderate dysfunction & 4 & 4.7 & 2 & 14.3 & & \\
\hline Moderate dysfunction & 2 & 2.3 & 5 & 35.7 & & \\
\hline Sever dysfunction & 4 & 4.7 & 1 & 7.1 & & \\
\hline
\end{tabular}

Male partners of non- compensated $\mathrm{CHC}$ female patients had lower scores of sexual functions in all items of sexual domains of IIEF than partners with compensated patients

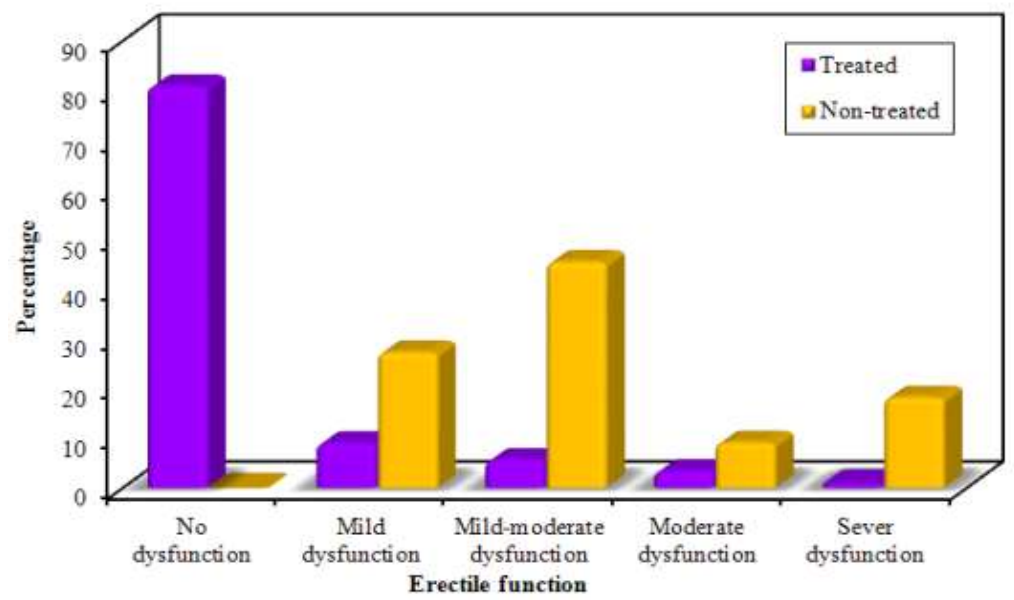

Fig (6) Relation between treatment status of female partners and erectile function of males in group $A(n=100)$ 


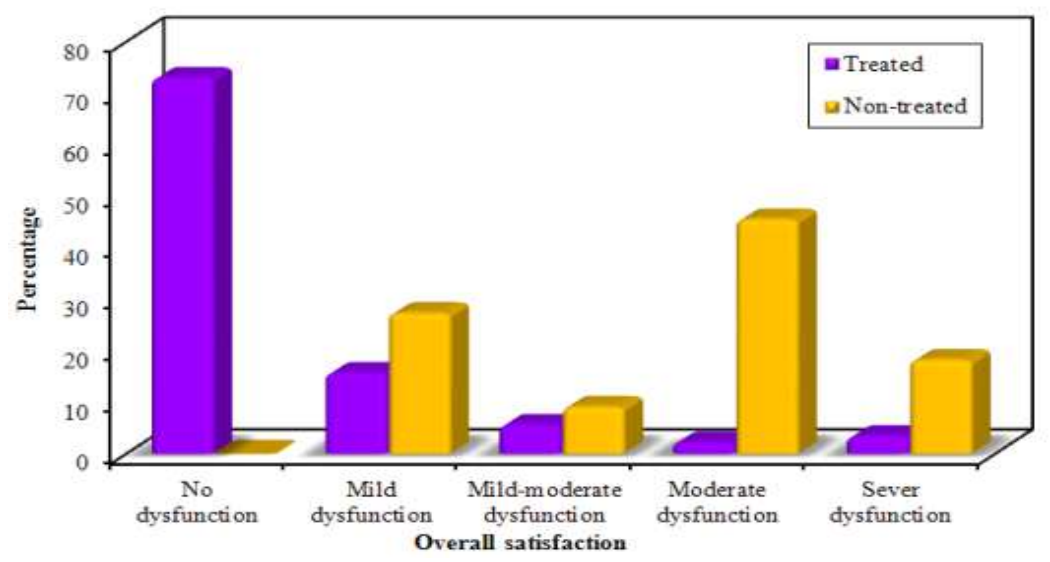

Fig (7) Relation between treatment status of female partners and overall satisfaction of males in group A $(n=100)$

\section{Discussion}

Egypt is the country with the highest HCV prevalence in the world; in 2008, the Egyptian Demographic Health Survey (EDHS), which was conducted on a large nationally representative sample, estimated the prevalence of $\mathrm{HCV}$ antibodies among the 15-59 years was found $14.7 \%$ (4). It has been postulated that the epidemic mainly due to extensive iatrogenic transmission during the era of parenteral-antischistosomal -therapy (PAT) mass-treatment campaigns which carried out in Egypt from 1950 to 1980 had led to an extensive transmission of HCV among persons alive during that campaign. HCV infection and its complications are among the leading public health challenges in Egypt [9].

To the best of our knowledge, this is the first study to evaluate sexual functions of males married to females with chronic hepatitis $\mathrm{C}$ infection in Egypt. To accomplish this target, this cross sectional study was conducted on 100 males $(<45$ years old) married to sexually active female partners having chronic hepatitis $\mathrm{C}$ (group A) and 100 age matched males married to healthy individuals as control (group B), all subjects were recruited from Banha University Hospital (hepatology unit) and National Liver Institute at EL-Menofia during the period from January 2017 to December 2018.

In this study, we observed non statistically significant difference in sexual functions in males married to females with chronic hepatitis $\mathrm{C}$ compared with control group.

This result can be explained by the fact that men usually want to have and think about sex more often than women, report more frequent sexual fantasies and report greater feeling of sexual desire [10] .

It has been generally assumed that sexual function may be influenced over time as a function of both internal (e.g. physical, mental health, hormonal) and external e.g. situational factor [11].
In this study, male partners did not suffer from any organic or psychological diseases causing sexual dysfunction to them.

In addition to, male partners in this study understand the nature of disease and mode of transmission and know the fact that $\mathrm{HCV}$ is not classified as a sexual transmitted infection [12].

These results were in agreement with the results of [13]' who reported that the incidence of ED was 33/1000 person years among 40-49 years old men and 190/1000 person years among 60-70-years old men. Also this was in agreement with [14], who reported that the prevalence of men who have intercourse less than once a month was 11.1-15.3\% in the younger age groups (23-39 years), 22.2$25.1 \%$ in the middle age groups (40-59 years) and $44.7-68.8 \%$ in the older age groups (60-79 years), and the number of men with ED increased with advancing age. These results were also in agreement with [15], who reported that the prevalence and severity of ED increased with advancing age.

This result can be attributed to psychological and behavioral changes with aging which can all affect sexual functioning i.e. there are a wide range of physical illness (cardiovascular diseases, diabetes mellitus, hepatic diseases, disk herniation and cerebral infarction, hyperlipidemia, ...) and psychological conditions (anxiety, depression, fatigue, poor body image, ....) and their associated treatments that could possibly impair erectile function and these are increasingly common with advancing age [16]. As regard to geographical distribution, the present study shows that men live in urban areas $(n=45)$ had more dysfunction than rural counterparts $(n=55)$ in all types of sexual domains of IIEF.

This was in agreement with [17] who showed that urban areas had more ED $(65.1 \%)$ than did rural areas $(42.1 \%)$.

The result of our study was not in agreement with [18], who showed that men in rural areas 
reported more complete ED (15.5\%) than city dwellers $(11 \%)(\mathrm{P}<0.001)$.

This result can be attributed to the impact of socioeconomic factors on sexual functions, individuals in a higher socio-economic class are more prone to stress. This is because of their status and lifestyles, which have the tendency to predispose them to cardiovascular risk factors and other diseases [19].

When searching the association between occupation of male and sexual function, there was non -statistically significant difference as regard to occupation in all types of sexual domains of IIEF.

These finding are concordant with other studies [20], who showed non statistically significant difference as regards to occupation $(\mathrm{p}=0,285)$.

This result may reflect that human sexuality is the way people express themselves as sexual beings. This involves biological, erotic, physical, emotional, social or spiritual feeling and behaviors. These solid believes may not be affected by type or quality of occupation.

In this study, there was inverse correlation between the level of education of male and sexual dysfunction in both Erectile function domain $(\mathrm{p}=0,010)$, and orgasmic function domain $(\mathrm{p}=0,039)$.

The result of this study was in agreement with [18], who reported that ED was directly associated with lower level of education $(\mathrm{p}<0.001)$, but not in agreement with (21), who reported non-significant correlations between SD and level of education.

Regarding to age of female partners, the current study showed significant negative correlations between female's age and all types of sexual domains of IIEF.

This result was matched with the study done by [17], who reported that IIEF total score decreased with the increase in partner's age. Also [22]' reported that inverse associations between frequency of sexual intercourse and the partner's age.

This result can be attributed to the physiological alterations related to hormonal changes, psychological problems and physical illness associated with aging process [19].

In the present study, there is statistically significant difference between the studied groups in all types of sexual domains of IIEF as regard to occupation of the patient's wife i.e. husbands of working wives have more sexual dysfunction than husbands of nonworking wives.

This was in agreement of [17], who showed negative relation between occupation of female's partners and sexual function of their males in all types of sexual domains of IIEF $(\mathrm{P}=0.003)$.

When searching the association between the level of education of female partners and sexual function of male, there was inverse correlation between level of education and sexual dysfunction of male in all types of sexual domains.

This was in agreement with ${ }^{(23)}$, who reported an association between low education level and ED.

On the contrary, [24], showed a positive correlation between level of education and sexual dysfunction. [17], showed non-significant difference in sexual function of male as regard to education of his wife $(\mathrm{P}=0.917)$.

In this study, there was a significant negative correlation between the duration of HCV infection in females and sexual function reported by their male partners.

As the disease progress, Hepatitis C affects not only liver but also has extrahepatic manifestations. In severe cases where decompensation occurs, quality of life is severely deteriorated and this accordingly can affect sexual functions of patients.

In current study, we noticed that males married to female partners who receive treatment of $\mathrm{HCV}$ had high scores of sexual functions than males married to untreated female partners regarding to all items of sexual domains of IIEF ( $p<0,001)$.

These results were in agreement with [25]. Who reported that successful antiviral treatment such as interferon plus ribavirin may improve such $\mathrm{SD}$ in patients with chronic HCV infection.

On the contrary, [26]. found that patients affected by $\mathrm{HCV}$ treated with recombinant human interferon alfa-2b, alone or in a combination with ribavirin, developed an overall increase in depressive state during the treatment, with a proportional increase in loss of libido. Furthermore, another research group reported significant decline in sexual function at week 12 of combination treatment that gradualy improved within 48 weeks after treatment [27].

In general, every patient with chronic hepatitis $\mathrm{C}$ should receive antiviral therapy to reduce the risk of hepatocellular carcinoma, liver decompensation, liver-related mortality and even all-cause mortality as well as improve liver histology [28].

\section{Conclusion}

The results of this study provide quantifiable risk information for counseling long-term monogamous heterosexual couples in which one partner has chronic $\mathrm{HCV}$ infection. In addition to the extremely low estimated risk for HCV infection in sexual partners, the lack of association with specific sexual practices provides unambiguous and reassuring counseling messages.

\section{References}

[1] L.Lewis, R.Wiliam, M.Fugl, K.Sam, R. Bosch, A.R. Fugl: Definitions, classification, and epidemiology of sexual dysfunction. Sexual medicine: sexual dysfunction in men 
and women, paris health puplication .Vol 37, PP.72, 2009.

[2] C.H.N. Abdo, W.M.Olivera, W.M. Moreira, A. Danoff: Prevalence of Sexual Dysfuncitons and Correlated Conditions in a Sample of Brazilian Women: Results of the Brezilian Study on Sexual Behavior (BSSB). International Journal of Impotence Reseach,Vol 16, PP. 160$166,2005$.

[3] K.Heiman and R.Jac :Sexual Dysfunction: Overview of Prevalence, Etiological Factors, and Treatments. The Journal of Sex Reseach; 39: 73-78,2007.

[4] A.Kandeel., M.Genedy., S. El-Refai, L.Anna, S.Funk, F.Arnaud. :Egypt and ICF International.Liver Int.; Vol 37,PP. 4553,2015 .

[5] A. Kim : Hepatitis C Virus. Annals of internal medicine (Review), Vol 163(11), PP. 818$826,2016$.

[6] M.R.krauss,: Sexual dysfunction in the male with chronic hepatitis c, antiviral therapy and interferon induced functional androgen deficiency or depression. Journal of endocrinology; Vol 143,PP.371-374.2007

[7] A.Danoff, : Sexual Dysfunction is Highly Prevalent Among Men with Chronic Hepatitis C Virus Infection and Negatively Impacts Health-Related Quality of Life. The American Journal of Gastroenterology,Vol 101,PP12351243,2008.

[8] R.C.Rosen, A.Riley, G.Wagner, , I.H.Osterloh, J.Kirkpatrick and A.Mishra :The international index of erectile function (IIEF): a multidimensional scale for assessment of erectile dysfunction. Urology, Vol 49, PP.822$826,1997$.

[9] F.D.Miller and L.J.Abu-Raddad :Evidence of intense ongoing endemic transmission of hepatitis $\mathrm{C}$ virus in Egypt. ProcNatl AcadSci USA,Vol107 (33),PP.14757-14762,2010

[10] E.A.Impett, A.Strachman, E.J. Finkel and S.L. Gable: Maintaining sexual desire in intimate relationship: the importance of approach goals. J Pers Soc Psycol;Vol 94 (5),PP.808-823,2008.

[11] P.C.Regan and L.Atkins : Sex differences and similarities in frequency and intensity of sexual desire. Soc Behav Pers, Vol 34, PP.94102,2006.

[12] E.K.Gough, M.C.Kempf, E.Chamot Hepatitis C Virus transmission risk in incarcerated or detained populations. Hepatology, Vol 59(2),PP.720-733,2014.

[13] E.D.Moreira, C.F.Lbo, A.Diament, A .Nicolosi, D.B.Glasser. : Incidence of ED in men 40 to 69 years old: results from a population-based cohort study in Brazil.Urology,Vol 61,PP.431-436,2003.

[14] M.Marumo, J.Ken, N.Jun, and M. Masaru: Age-related prevalence of erectile dysfunction in Japan: Assessment by the International Index of Erectile Function." International journal of urology ,Vol 8.2,PP. 53-59,2001.

[15] S.A.Grover, I.Lowensteyn,M. Kaouache, S.Marchand, L.Coupal, E.DeCarolis, : The prevalence of ED in the primary care setting: importance of risk factors for DM and vascular disease. Arch Intern Med,Vol 166,PP. 213219,2006.

[16] M.E.Camacho, C.A.Reyes:Sexual dysfunction in the elderly: age or disease? International journal of impotence research,Vol 17,PP.(S1): S52,2005.

[17] M.F.Taghreed, H.Alaa. M.Maraeeb, N.Nagwa, A.Hegazyb and I.Ibrahim:Quality of life in patients with erectile dysfunction in Shebin El Kom District. Menoufia Medical Journal,Vol 30(2),PP. 607,2017.

[18] R.M.Seyam, A.Albakry, A. Ghobish, H .Arif, K. Dandash and H.Rashwan. Prevalence of erectile dysfunction and its correlates in Egypt: a community-based study. Int J Impot Res, Vol 15,PP.237-245,2003.

[19] K.L.Billups, A.J.Bank, H.Padma- Nathan, S.D.Katz and R.A.Williams: Erectile dysfunction as a harbinger for increased cardio-metabolic risk". Int. J Impot Research.,Vol 20,PP. 236-242,2008.

[20] E.Akkus, A.Kadioglu, A.Esen, S .Doran, A.Ergen, K.Anafarta :Prevalence and correlates of erectile dysfunction in Turkey: a population -based study. Eur Urol, Vol 41,PP.298304,2002 .

[21] A.Danoff, O.Khan, D.W.Wan :Sexual dysfunction is highly prevalent among men with chronic hepatitis $\mathrm{C}$ virus infection and negatively impacts health-related quality of life. Am J Gastroenterol, Vol 101,PP. 1235$1243,2006$.

[22] K.Hawton: Sex Therapy: A Practical Guide. Oxford University Press, New York, NY,Vol 43,PP.123-1991985. 
[23] A.M.Elnashar: Female sexual dysfunction in Lower Egypt." BJOG: An International Journal of Obstetrics \& Gynaecology,Vol 114.2,PP. 201-206,2007.

[24] J.M.van Gleen, P.H. van de Weijer and H.T.Arnolds (1996). Urogenital symptoms and their resulting discomfort in noninstitutionalized 50-to-75-years-old Dutch women. Ned Tijschr Geneeskd,Vol 140, pp713-16,1996.

[25] M.Malaguarnera, E.Vicari, A .Calogero: Sexual dysfunction in chronic hepatitis $\mathrm{C}$ virus patients treated with interferon alpha and ribavirin. $\mathbf{J}$ Interferon Cytokine Res,Vol 28,pp 603-609,2008.
[26] M.R.Kraus, A.Schäfer, T.Bentink : Sexual dysfunction in males with chronic hepatitis $\mathrm{C}$ and antiviral therapy: interferon-induced functional androgen deficiency or depression? J Endocrinol,vol 185,pp345-52,2005.

[27] N.Fawzy, H.Atia, S.Galal : Prevalence and risk factors of erectile dysfunction among chronic hepatitis $\mathrm{C}$ male patients treated with pegylated interferon- $\alpha$ and ribavirin. Egypt $\mathrm{J}$ Psychiatry, Vol 36,PP.40-4,2015.

[28] L.I.Backus, D.B.Boothroyd, B.R. Phillips:A sustained virologic response reduces risk of allcause mortality in patients with hepatitis $\mathrm{C}$. Clin Gastroenterol HepatolVol 9,PP.509$516,2011$. 